\title{
Ecologia de mosquitos (Diptera: Culicidae) em criadouros naturais e artificiais de área rural do Norte do Estado do Paraná, Brasil. I - Coletas ao longo do leito de ribeirão*
}

\author{
Mosquito (Diptera: Culicidae) ecology of natural and artificial rural breeding \\ places at North Paraná State, Brazil. 1 - Collections in a bed-streamlet
}

\author{
José Lopes, Ana L. Lozovei \\ Departamento de Biologia Animal e Vegetal da Universidade Estadual de Londrina - Brasil (J.L.) \\ Departamento de Patologia Geral da Universidade Federal do Paraná - Brasil (A.L.L.)
}

\begin{abstract}
Objetivando-se conhecer as espécies de Culicidae aptas a colonizarem ambiente de um ribeirão com mata ciliar reduzida $\theta$ localizado na região Sul do Brasil, foram realizadas capturas com auxillo de rede para coleta de insetos aquáticos. Foram apanhadas as seguintes espécies: Aөdes crinifer, Aөdomya squamipennis, Anopheles fluminensis, An. intermedius, An. albitarsis, An. argyritarsis, An. evansae, An. galvaoi, An. oswaldoi, An. strodei, An. triannulatus, Chagasia tajardi, Culex bidens, Cx. grupo coronator, Cx. eduardoi, Cx. mollis, Cx. quinquefasciatus, Cx. coppenamensis, Cx. vaxus, Cx. grupo inhibitator, Cx. intrincatus, Cx. (Melanoconion) sp., Psorophora saeva (?) e Uranotaenia puicherrima. Para as espécies em que fol capturada uma amostra tida como representativa, foram estudadas a distribuiçāo ao longo da área pesquisada, a flutuaçāo populacional e a correlaçāo com fatores físicos do ambiente. Conclui-se da anàlise que massas de água orladas por mata ciliar reduzida podem funcionar como refúgio para alguns Culicidae e esta condiçăo pode contribuir decisivamente para o processo de domiciliaçāo de espécies deste grupo.
\end{abstract}

Culicidae. Ecologia de Vetores. Larva

\section{Introdução}

Os levantamentos científicos relativos às populaçōes de insetos, no Norte do Paraná, só começaram a acontecer depois da colonizaçāo humana da região. Conseqüentemente, informações relativas às condições ambientais primitivas ficam restritas a pequenas reservas remanescentes e que necessariamente não seriam representativas da situação original.

A sobrevivência de uma população animal, ou parte dela, em ambiente alterado pelo homem pode estar correlacionado ao processo de domiciliação.
Gomes ${ }^{10}(1986)$ teoriza que a domiciliaçāo é resultante de fatores tanto biológico-naturais como antropogênicos. É um fenômeno essencialmente biológico, pois tem sua origem alicerçada principalmente em fatores intrínsecos e, secundariamente, em fatores extrínsecos, responsáveis apenas pela influência no padrão do processo de desenvolvimento evolutivo da espécie.

No Paraná, Andrade \& Rachou' (1954) e Lozovei e Luz's (1976), Silva e Lopes ${ }^{19}$ (1985) e Lopes e col. ${ }^{3}(1993)$ realizaram levantamentos de espécies de Culicidae que procriavam em criadouros naturais e artificiais, e encontraram, entre

\footnotetext{
* Parte de Tese de Doutorado de José Lopes, apresentada ao Curso de Pós-Graduação em Entomologia da Universidade Federal do Parana, em 1992, sob o titulo: "Ecologia de mosquitos (Diptera: Culicidae) que procriam em criadouros naturais e artificiais em área rural, Londrina e Cambe, Parana, Brasil" Apresentado no XX Congresso Brasileiro de Zoologia. Rio de Janeiro, 1994. Separatas/Reprints: José Lopes - Universidade Estadual de Londrina - Compus Universitário - Caixa Postal 6001 - 86051-970 Londrina, PR - Brasil - Fax: (0432) 27.6932

Recebido em 28.6.1994. Aprovado em 10.4.1995
} 
outras espécies, Anopheles albitarsis, An. strodei, An. argyritarsis, An. triannulatus, Aedes crinifer, Aedomya squamipennis, $C x$. coronator, $C x$. quinquefasciatus e $C x$. mollis.

Planejou-se identificar as espécies que procriam em um ribeirāo, bem como em criadouros artificiais instalados na mata ciliar que margeia o curso d'água e naqueles resultantes de utensílios descartados pelo homem ou originados por meio de circunstâncias diversas nos peridomichlios circunvizinhos.

Também foram estabelecidas metas para a identificaçăo de espécies hematófagas e respectivas periodicidades diárias de picada, através do uso de isca humana.

Paralelamente, foi objetivada a obtenção de informaçōes bionômicas a respeito das populaçōes das espécies encontradas em diferentes tipos de biótopos, suas variaçōes estacionais, suas preferências por diferentes tipos de criadouros, a influência dos biótopos sobre estas populaçôes, suas associaçőes interespecíficas e a influência de alguns fatores climáticos sobre elas.

$O$ presente trabalho refere-se aos resultados de imaturos de Culicidae coletados ao longo do
Ribeirão São Domingos, visando a avaliar o seu potencial como criadouro desses mosquitos e, concomitantemente, saber quais dentre as espécies estariam aptas para colonizar biótopos com condiçōes semelhantes.

\section{Materlal e Método}

A bacia do Ribeirão Cafezal, da qual faz parte - Ribeirão São Domingos, área onde se desenvolveu a presente pesquisa, está situada a Sudeste da cidade de Londrina, Paraná, Brasil (Fig. 1).

O clima desta regiāo é do tipo subtropical úmido, segundo C. Troll. De acordo com Maack ${ }^{16}$ (1981), a temperatura média anual é igual a $20,6^{\circ} \mathrm{C}$, sendo janeiro o mês mais quente, com temperatura média de $23,8^{\circ} \mathrm{C}$, enquanto julho é o mais frio, com média de $16,8^{\circ} \mathrm{C}$. $\mathrm{O}$ índice pluviométrico médio anual do Município de Londrina é de $1.439,8 \mathrm{~mm}$, com maiores precipitaçōes no verão. A umidade relativa média anual é da ordem de $73 \%$ e a insolação total é estimada em $2.559,5$ horas/ano.

O leito do Ribeirāo Sảo Domingos apresenta uma extensão aproximadamente de $11 \mathrm{~km}$, com
A

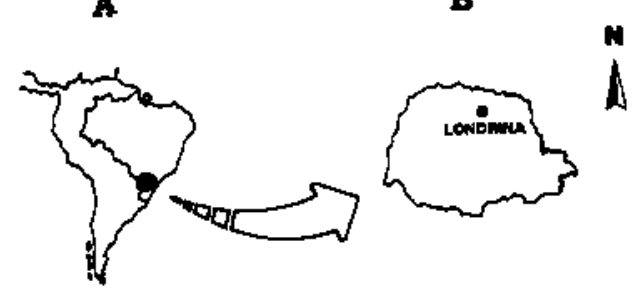

c

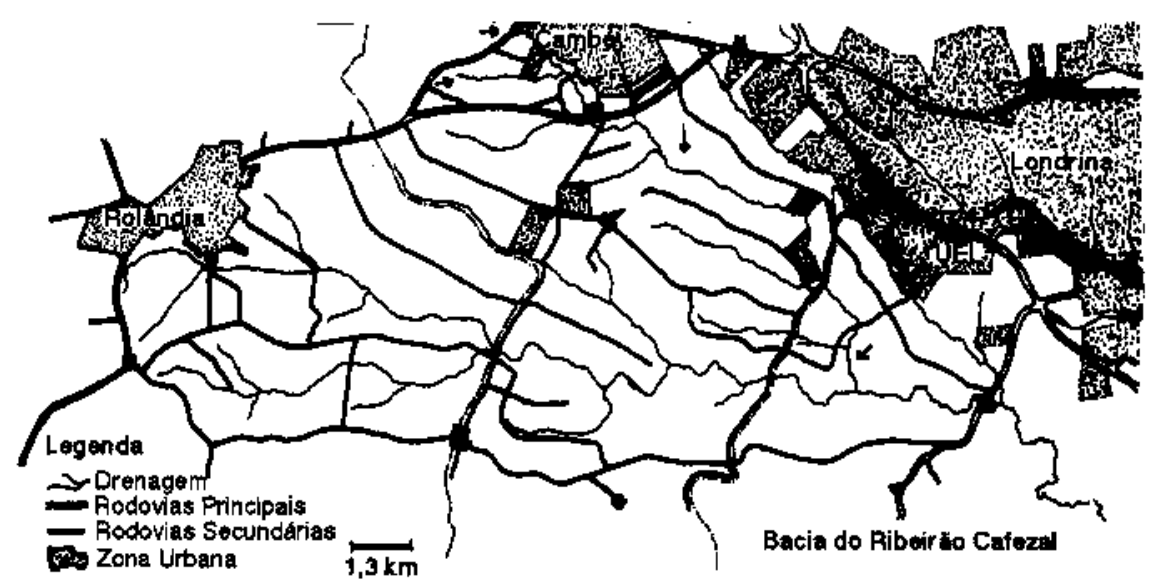

Flgura 1 - Locallzaçāo da área de estudo, detathando a Bacia do Ribeirāo Cafezal, da qual faz parte o Ribeirăo Sāo Domingos (indicado pelas setas), local da presente pesqulsa. 


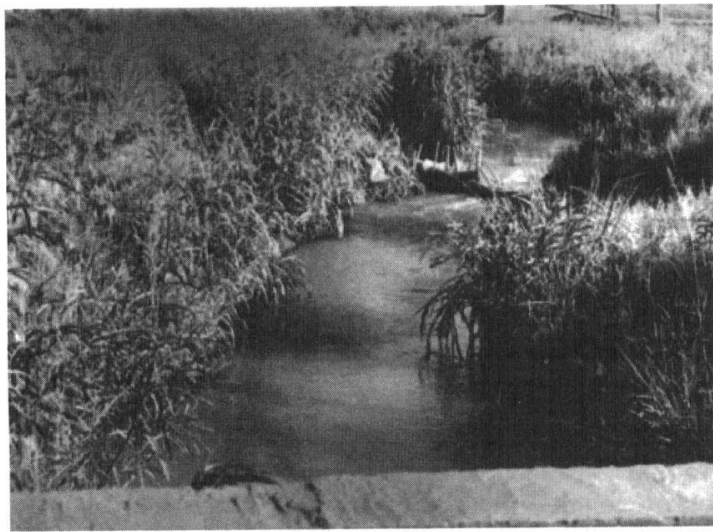

Figura 2 - Aspectos do Fibeirão São Domingos na estação de coleta número 5 .

largura média de $1,5 \mathrm{~m}$ e profundidade média de $0,80 \mathrm{~m}$ (Fig. 2). Na maior parte do seu curso, as águas correm em depressões do terreno, originárias de escavaçōes provocadas pela própria correnteza das águas. Os pontos de confluência com seus afluentes caracterizarm-se como baixios, que favorecem a formação de brejos.

A mata ciliar acompanha quase toda a extensão do ribeirão e caracteriza-se como mata de regeneração, embora também ocorram algumas árvores de médio e grande porte. A largura média dessa mata ciliar é de $5 \mathrm{~m}$ em cada margem.

Além dos limites da mata ciliar, a paisagem é predominantemente de pastagens ou de áreas agriculturáveis, onde é comum a aplicação de agrotóxicos.

As coletas junto ao Ribeirão São Domingos foram efetuadas uma vez por mês, de julho de 1988 a junho de 1989 . Foram determinadas 5 estações ao longo da sua margem direita (Fig. 3). As capturas foram realizadas com rede ento-

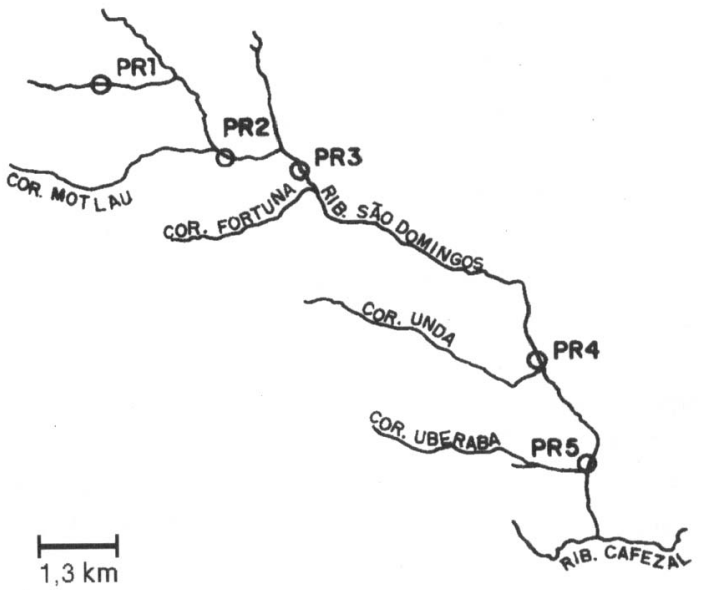

Figura 3 - Bacia do Ribeirão São Domingos. PFl=estação de coleta.

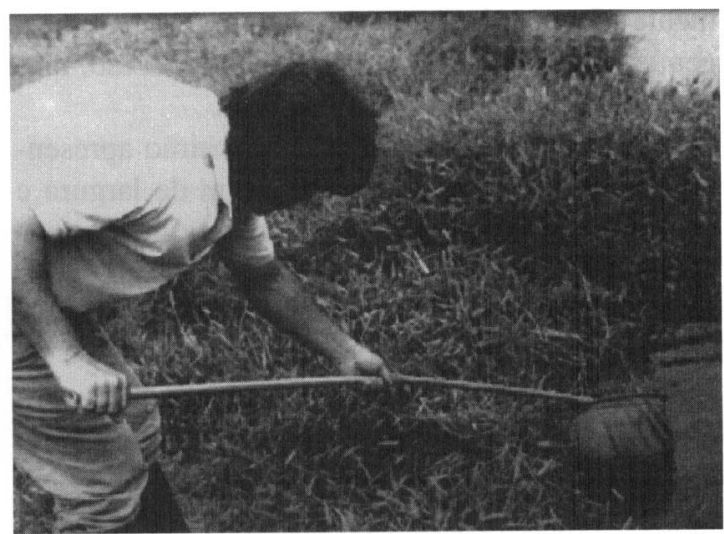

Figura 4 - Aspecto da operação da rede de coleta aquática.

mológica para insetos aquáticos, dotada de um cabo de $3 \mathrm{~m}$ de comprimento o que possibilitava operar em locais de difícil aproximação (Fig. 4). $\mathrm{O}$ cabo era de alumínio e composto por 3 segmentos, acopláveis através de sistemas de luvas e roscas e tinha na extremidade a fixação de uma armação de ferro em forma da letra $D$, com $53,5 \mathrm{~cm}$ de diâmetro maior e $23 \mathrm{~cm}$ de diâmetro menor. A esta armação era adaptado um saco com $20 \mathrm{~cm}$ de profundidade central: $o$ tecido era algodão e as bordas eram arrematadas com um reforço de lona, para aumentar a resistência na regiāo de contato com o aro de ferro.

Em cada uma das estações de coleta foi constituída uma amostra de 20 lances da rede. A cada lance, o conteúdo era despejado em uma bandeja, de onde eram recolhidas as larvas de quarto ínstar e as pupas. No laboratório, as larvas e pupas eram contadas e preservadas para a obtençāo de adultos, com vistas às identificações. As exúvias do quarto ínstar foram montadas em lâminas, enquanto que os adultos correspondentes o foram em triângulos fixados por alfinetes entomológicos.

As estações de coleta ao longo do ribeirão mostravam as seguintes carcaterísticas:

Estação 1 (Fig. 3-PR1): O ribeirāo se alargava, chegando a aproximadamente $5 \mathrm{~m}$ de largura. Conseqüentemente, a profundidade média era reduzida em torno de $0,20 \mathrm{~m}$ e a correnteza era branda. Quase $90 \%$ da área apresentava vegetação aquática, composta príncipalmente por Eichhornia azurea (aguapé), Coik lacrimae-jobi L. (rosário), Ludwigia sp, além de capim nativo, cujas raízes fixavam-se no leito. A mata ciliar estava presente apenas na margem esquerda, uma vez que na direita havia uma pequena interrupção desta vegetação, com a pastagem chegando até a água. A mata ciliar era formada por árvores com aproximada- 
mente $15 \mathrm{~m}$ de altura; em geral eram árvores emergentes, notando-se estrato herbáceo reduzido, mas com arbustos em desenvolvimento .

$\mathrm{Na}$ estação 2 (Fig. 3-PR2) o ribeirão apresentava-se estreito, chegando até a $1 \mathrm{~m}$ de largura e exibindo uma correnteza ligeiramente mais acentuada do que a do PR1. Não havia vegetação aquática neste local. A profundidade oscilava em tomo de $0,80 \mathrm{~m}$, havendo mata ciliar apenas na margem esquerda. A vegetação das margens era formada principalmente por capim e Coik lacrimae-jobi, que pendiam sobre a superficie líquida, estabelecendo uma espécie de cobertura.

$\mathrm{Na}$ estaçāo 3 (Fig. 3-PR3) havia uma represa formada em conseqüência de uma barragem no ribeirão; a mata ciliar estava ausente e áreas de pastagem ocupavam toda a margem (Fig. 2). Grande quantidade de vegetação aquática dominava a faixa marginal da superfície líquida. A largura média ficava em torno de $50 \mathrm{~m}$, e a profundidade era variada, chegando a atingir até $2 \mathrm{~m}$ no meio do leito. A massa de água apresentava-se basicamente parada e recebia incidência solar direta. As principais macrófitas aquáticas eram representadas por Salvinia sp, Cyperus sp e Hedychium coronarium Koen. Próximo ao represamento havia também uma nascente que dava origem a um pequeno poço, o qual era circundado por árvores, formando uma minúscula concentração de vegetação exuberante.

A estaçăo 4 (Fig. 3-PR4) correspondia ao lugar da desembocadura do Córrego Unda e exibia vestígios de mata ciliar. No aspecto físico era um brejeiro, com muito capim nativo e que ficava totalmente alagado nas épocas de cheia. Esse fenômeno que era favorecido ainda mais pela presença de uma ponte que provocava o afunilamento do leito. Todo o baixio correspondia a aproximadamente $700 \mathrm{~m}$ de largura e nesse ponto o ribeirão caracterizava-se por água corrente, com aproximandamente $1,5 \mathrm{~m}$ de largura e $1,2 \mathrm{~m}$ de profundidade e dotado de vegetação na margem (capim) que avançava sobre a superfície d'água.

$\mathrm{Na}$ estaçāo 5 (Fìg. 3-PR5) não ocorria mata ciliar e o contorno do ribeirão apresentava-se bastante irregular, com a largura variando entre 1 e 4 m (Fig. 2). Esta variação era devida à existência de uma ponte que causava um afunilamento do curso d'água e também à proximidade do local de desembocadura do Córrego Uberaba. A profundidade variava entre 1 a $1,5 \mathrm{~m}$. A vegetaçăo das margens era constituída por capim coloniāo, capim gordura, capim nativo, C. lacrimae-jobi e Ludwigia $\mathrm{sp}$, que invadiam o início do leito. A margem esquerda cracteriza-se por ser um brejeiro de mais ou menos $80 \mathrm{~m}$ de largura.

\section{Resultados e Dlscussão}

Foram coletadas 2.764 larvas de Culicidae. A Tabela 1 relaciona as espécies, a sua distribuiçăo quantitativa nas estações de coleta.

Tabela 1 - Número total de individuos coletados para cada espécie entre 07/88 e 06/89 nos cinco diferentes pontos de coleta (PA) distribuidos ao longo do Ribelræ̌o São Domingos, nos Municíplos de Cambé e Londrina (PR).

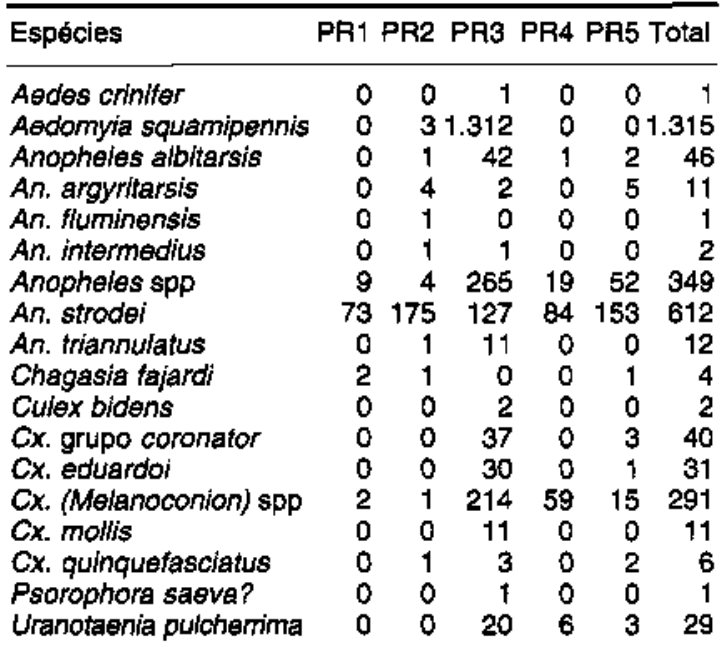

Total

B6 $1932.079 \quad 169 \quad 2372.764$

O PR3 (represa) mostrou-se o ponto mais produtivo, contribuindo com $75,3 \%$ do total das larvas recolhidas e também o que apresentou maior diversiadade, assinalando-se 18 espécies; destas, seis foram exclusivas deste local. Por outro lado, 0 PR 1 foi o menos produtivo, perfazendo apenas $3 \%$ do total e tambem foi o que apresentou a menor diversidade de espécies (apenas 4), das quais somente uma foi exclusiva.

$\mathrm{Na}$ somatória geral de Culicidae que compuseram a amostra, a predominância foi de Aedomyia squamipennis com $48 \%$, mesmo sendo capturada praticamente só na represa.

Pertencentes a $C x$. (Melanoconion) foram apanhadas $C x$. coppenamensis, $C x$. vaxus, $C x$. grupo inhibitator, $C x$. intrincatus e $C x$. (Melanoconion) sp. Todavia, dado às dificuldades encontradas na sistemática desses culicídeos, optou-se por agrupá-las como $C x$. (Melanoconion) spp para efeito dos tratamentos quantitativos. 
Dificuldade semelhante envolveu a distinçâo entre An. evansae, An. galvaoi e An. oswaldoi na fase larval. Embora a presença das três espécies tenha sido comprovada pela identificação de adultos, tanto machos quanto fêmeas, decidiu-se agrupá-las como Anopheles spp prevenindo-se assim quanto a eventuais erros em interpretações e conclusões.

Ainda a Tabela 1 observa-se que acusa Anopheles spp e An. strodei estão presentes nos 5 diferentes ecótopos, o que mostra a ampla distribuição ao longo desta reduzida mata ciliar. Por outro lado, Ae. crinifer, An. fluminensis, Culex bidens, $C$. coppenamensis, $C x$. grupo inhibitator, $C x$. intrincatus, $C x$. mollis e Psorophora saeva (?) mostraram especificidade em relação a determinados pontos.

An. strodei predominou nas estaçōes $1,2,4$ e 5 representando respectivamente, $85,91,50$ e $65 \%$ das larvas af capturadas. Todavia nāo mostrou preferência por um determinado local, fato comprovado pela nāo-significância apontada pelo teste de análise de variância.

$\mathrm{Na}$ estação 3 , o predomínio foi de $A d$. squamipennis com $63 \%$ dos indivíduos. Com relação a esta espécie tornou-se dispensável a análise estatística referente à preferência por algum tipo de ambiente, já que $99,7 \%$ foram encontradas na represa. $\mathrm{O}$ mesmo aconteceu com Anopheles spp, An. albitarsis e $C x$. (Melanoconion) spp que apareceram nesse local em percentuais de $75,9,93,0$ e $73,5 \%$, de seus respectivos totais.

An. strodei foi a espécie mais freqüentemente coletada, aparecendo em $83,3 \%$ das operações de captura; tamberm figurou como a segunda em abundância, com elevada incidência nas estaçð̌es 2,3 e 5. A espécie mais abundante foi $A d$. squamipennis, que representou $47,5 \%$ de todo o material coletado; todavia, foi somente a quarta em frequiência, porque esteve praticamente restrita a estaçāo 3.

Anopheles spp mostraram preferências por água parada entremeada com vegetação e recebendo incidência solar direta. An. strodei foi mais abundante na estação 2, onde o riacho tinha leve correnteza. Essa preferência por habitats ensolarados foi anteriormente assinalada para An. galvaoi e An. strodei, por Lane ${ }^{12}$ (1936), Cerqueira ${ }^{14}$ (1961) e Lozovei e Luz's (1976).

Ae. crinifer, An. fluminensis, An. intermedius, An. triannulatus, Ch. fajardi, $P$ s. saeva (?), $C x$. bidens, $C x$. coppenamensis, $C x$. vaxux, $C x$. grupo inhibitator, $C x$. intrincatus e $C x$. (Melanoconion) sp, apareceram escassamente nesse tipo de habitat, pela metodologia de coleta adotada. É provável que a mata ciliar reduzida, que é como se caracterizava a regiāo, e as condiçôes gerais do ribeirāo, nāo tenham sido suficientes para atender às peculiaridades fisiologicas e comportamentais de tais espécies. Portanto, elas não estariam adaptadas a um ambiente antropogênico com alto grau de devastação, como onde se desenvolveu o estudo.

Entretanto o registro dessas cinco espécies de $C x$. (Melanoconion) reveste-se de importância pelo fato de se tratar da primeira vez que elas estão sendo assinaladas no Sul do Brasil. Somam-se a elas, também $C x$. bidens e Ur. pulcherrima.

Na região anazônica, An. triannulatus havia sido coletado em poças e lagoas dotadas de vegetação e ensolaradas Cerqueira ${ }^{4}$ (1961), à semelhança do que foi observado na presente pesquisa. Para $C h$. fajardi, embora em frequiência muito baixa, observou-se a sua presença onde a água do ribeirāo apresentava-se com uma correnteza moderada e havia vegetaçāo apenas nas margens ou já no leito, mas fortemente enraizadas no fundo. Larvas desta espécies já foram encontradas em charcos, riachos de pouca correnteza, lagos, grandes alagados de água limpa e depressões de cascos de animais (Cerqueira4, 1961; Lourençode-Oliveira e col. ${ }^{14}, 1986$ ).

As espécies $C x$. quinquefasciatus, $C x$. mollis, $C x$. grupo coronator $\mathrm{e} A$. argyritarsis são amplamente conhecidas como adaptadas a se desenvolver em água acumulada em recipientes, inclusive na área urbana. Esta é uma indicaçāo de adiantados processos de adaptação ao ambiente antropogênico e consequiente domiciliaçāo. Esta caracterisação explica a baixa freqüência de tais espécies no criadouro natural onde se deram as capturas.

Visando a verificar a existência de flutuação populacional nas espécies mais freqüentes, foi aplicado o teste de análise de variância para os totais mensais coletados para cada uma delas, sendo os valores transformados em raiz $(x+0,5)$ (Tabela 2). Para An. strodei o teste acusou significância em nível de $5 \%(\mathrm{P}<0,05)$, e o teste de Duncan contrastou as médias dos meses de abril, maio e junho, Lozovei e Luz $^{15}$ (1976) haviam relatado o encontro de larvas de An. strodei em açudes e brejos, nos arredores de Curitiba-PR, ao longo de todo $o$ ano.

Já para Anopheles spp não foi apontada significância. Contudo, destacou-se o mês de junho como o mais produtivo, com $23,5 \%$ do total anual. An. albitarsis foi pouco coletado, com freqüências 
Tabela 2 - Coleta mensal de Culicidae ao longo do leito do Plbeirăo Săo Domingos, localizado no Norte do Paraná, Brasil.

\begin{tabular}{lrrrrrr}
\hline Meses & $\begin{array}{c}\text { An. } \\
\text { strodei spp }\end{array}$ & An. & $\begin{array}{c}\text { An. } \\
\text { albitarsis }\end{array}$ & $\begin{array}{c}\text { Ad. } \\
\text { squami- } \\
\text { pennis }\end{array}$ & $\begin{array}{c}\text { Cx. } \\
(\text { Culex) }\end{array}$ & $\begin{array}{c}\text { Cx. } \\
\text { (Melano- } \\
\text { Conion) }\end{array}$ \\
& & & & & & \\
Jul & 28 & 20 & 0 & 109 & 1 & 2 \\
Ago & 60 & 10 & 5 & 56 & 6 & 7 \\
Set & 64 & 41 & 2 & 75 & 50 & 7 \\
Out & 45 & 20 & 1 & 246 & 17 & 19 \\
Nov & 17 & 4 & 2 & 115 & 3 & 5 \\
Dez & 68 & 41 & 3 & 247 & 9 & 19 \\
Jan & 4 & 9 & 6 & 204 & 0 & 28 \\
Fev & 6 & 23 & 0 & 80 & 5 & 0 \\
Mar & 40 & 24 & 4 & 48 & 0 & 32 \\
Abr & 77 & 26 & 2 & 26 & 0 & 60 \\
Mai & 125 & 49 & 4 & 30 & 0 & 65 \\
Jun & 78 & 82 & 17 & 79 & 0 & 47 \\
\hline Total & 612 & 349 & 46 & 1.315 & 90 & 291 \\
\hline
\end{tabular}

sempre baixas e distribuição abrangendo praticamente todo o ano, nåo sendo encontrado apenas nos meses de julho e fevereiro. A coleta de maior rendimento deu-se no mês de junho de 1988, com $37,8 \%$ do total. Com relação a $C x$. (Melanoconion), a variância não foi estatisticamente significativa, apesar das maiores produtividades em abril e maio com 20,6 e $22,7 \%$, do total, respectivamente (Tabela 2 ).

O subgênero Culex demonstrou predominância no mês de setembro, portanto, no início da primavera, Silva e Lopes $^{19}$ (1985) tinham observado maior frequiência de $C x$. (Culex) nos meses de outubro a dezembro em recipientes de um cemitério na área urbana de Londrina.

A análise de regressão linear entre as espécies do gênero Anopheles e os fatores temperatura e precipitação, não apontou significância, e ambas as correlaçōes foram inversas para An. strodei $\mathrm{e}$ Anopheles spp. Já para $C x$. (Melanoconion), a análise também não acusou significância, mas a correlação foi inversa em relação à temperatura $\mathrm{e}$ direta para com a precipitação.

Analisando o comportamento das' espécies em relação às diferentes estações do ano, para $A n$. strodei foi demonstrada significância em nível de $5 \% \quad(\mathrm{P}<0,05)$ e o teste de Duncan separou as estações do outono e inverno, ficando com a menor produtividade o verão (Fig. 5). Para Anopheles spp a variância foi nāo-significativa, mas o inverno mostrou a maior média com $39,2 \%$ do total, seguido pelo outono com 28,0\% (Fig. 5). Esta alta densidade larval desses anofelineos no inverno sugere que essas cinco espécies recorrem a uma interessante estratégia de sobrevivência, permanecendo esta estaçāo do ano na forma larvária.

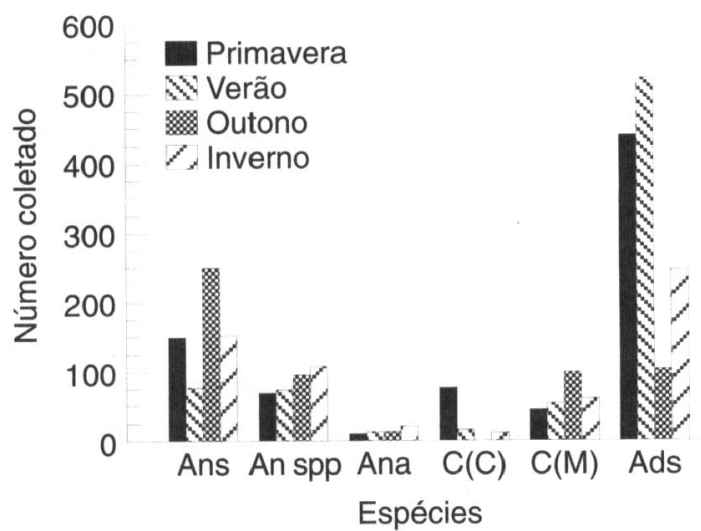

Flgura 5 - Variação populacional sazonal para as espé. cles mais freqüentemente coletadas no Ribeiržco são Domingos. (Ans $=A n$. strodei, An. spp $=$ Anopheles spp, Ana $=A n$. albitarsis, $C(C)=C x$. (Culex), $C(M)=C x$. (Melanoconion), Ads $=$ Ad. squamipennis.

An. albitarsis apareceu pouco nas capturas, sendo mais frequente no inverno. $C x$. (Culex) foi mais abundante na primavera. Por outro lado, o subgênero Melanoconion alcançou maior produtividade no outono (Fig. 5).

$\mathrm{Na}$ análise de regressåo linear, entre a quantidade de larvas coletadas nas diferentes estações do ano e os fatores físicos do ambiente, $A n$. strodei e $C x$. (Melanoconion) não apresentaram significância e tiveram correlação inversa. Anopheles spp, por sua vez, mostrou significância com temperatura e precipitação, de forma inversa, com $r=-0,9999+0,0795$ e $r=-0,9461+0,8950$, respectivamente.

A verificaçāo de alta densidade larval de $A n$. (Nysshorrynchus) e a sua distribuiçāo por toda a área de estudo constituíram forte indício de que elas sejam dotadas de razoável potencial de adaptação que lhes permitam colonizar biótopos alterados. As águas represadas, com incidência solar direta e com plantas aquáticas, são capazes de acolher altas densidades dessas espécies. Esta constatação se reveste de importância sociosanitária, uma vez que nos represamentos executados nos riachos e rios, as populaçóes de tais espécies podem se tomar abundantes e altamente perturbadoras do bem estar humano nas circunvizinhanças.

Ad. squamipennis atingiu a maior concentração de outubro a janeiro com evidente flutuação populacional. Para esta espécie nāo se justificou a aplicaçāo dos testes estatísticos, tendo-se em vista a clara preferência pelos meses de outubro, dezembro e janeiro, com percentuais anuais de 18,7, 18,7 e $15,3 \%$ respectivamente. $\mathrm{Na}$ análise de regressâo lin. ear, com relação aos fatores físicos do ambiente e a 
quantidade de larvas coletadas mensalmente, nāo foi detectada significância, e foi registrada correlação direta. Ad. squamipennis mostrou um padrāo específico de comportamento, estando a presença de suas larvas condicionada ao ambiente de água parada com plantas aquáticas e incidência solar direta. Observações semelhantes foram anteriormente realizadas por Dyar? (1928), Cerqueira ${ }^{4}$ (1961), Lozovei e Luz ${ }^{15}$ (1976) e Knight e Stone" (1977).

Esta espécie é sabidamente ornitófila (Gabaldon e col ${ }^{89} ., 1977$; Mitchell e col. ${ }^{17}$ 1987). Como conseqüência do seu grau de especialização quanto à sua alimentação e à reprodução, não se sugere qualquer indício de domiciliação. $O$ teste de análise de variância acusou resultado nåo-significativo com referência à sazonalidade. Todavia, Aedomya foi mais abundante no verăo com $40,2 \%$ do total, seguido da primavera com $33,2 \%$. Resultados semelhantes já haviam sido observados por Lozovei e Luz $^{15}$ (1976) que, inclusive, encontraram essa espécie em super população no verāo, em diques próximos à cidade de Curitiba.

Altas densidades populacionais de mosquitos podem provocar ao homem situação de desconforto ocasionada pelas picadas. Outros fatores socioeconômicos como as reações alérgicas às próprias picadas ou aos inseticidas aplicados, a transmissão de doenças e o dispêndio de verbas pelas pessoas e pelos órgãos govemamentais em açāo de combate ao inseto, assumem importância de ordem prática. Entre as espécies mais coletadas, An. albitarsis é considerada como transmissora primária da malária e An. strodei, An. evansae, An. galvaoi e An. oswaldoi, como vetores secundários do Plasmodium (Corrêas, 1938; Corrêa e col'., 1949; Rachou', 1958; Cerqueira4, 1961; Andrade e col ${ }^{1}$, , 1986; Tadei ${ }^{20}, 86 / 87$ ). Ad. squamipennis foi considerado como o principal vetor da malária

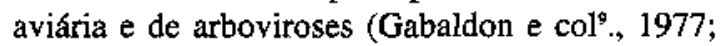
Calisher e $\mathrm{col}^{3} .$, 1988).

\section{Conclusões}

1 - Ae. crinifer, An. fluminensis, An. intermedius, An. triannulatus, Ch. fajardi, Ps. saeval?? e $C x$. bidens foram encontradas em baixa frequiência e abundância nas águas do Ribeirão São Domingos, sugerindo tratar-se de espécies pouco adaptadas a ambientes antropogênicos como o da região estudada.

$2-C x$. quinquefasciatus, $C x$. mollis, $C x$. grupo coronator e An. argyritarsis também foram pouco abundantes neste tipo de criadouro. Essas espécies sāo amplamente conhecidas como adaptadas a procriarem em recipientes encontrados nos peridomićlios. Este comportamento pode indicar adiantado processo de adaptação ao ambiente antropogênico e conseqüentemente à domiciliaçāo.

3 - A alta densidade populacional de An. strodei, An. evansae, An. galvaoi, An. oswaldoi e An. albitarsis e as suas distribuiçôes por diferentes tipos de ecótopos sugerem que elas sejam dotadas de suficiente plasticidade genética, 0 que as habilita a colonizar biotopos alterados.

4 - As espécies do subgênero Melanoconion ( $C x$. coppenamensis, $C x$. vaxus, $C x$. grupo inhibitator, Cx. intrincatus e $C x$. (Melanoconion) sp, pela fraca adaptabilidade à área de mata ciliar reduzida, conservam características comportamentais típicas de mosquitos de hábito silvestre.

5 - Ad. squamipennis foi a especie mais abundante e também mostrou especialização de comportamento, sendo encontrada unicamente em água parada com grande quantidade de vegetação aquática, principalmente Pistia stratiotis L. Esse mosquito estaria adaptado a ambientes antropogênicos mas ainda sem características de domiciliação, devido às exigências alimentares e quanto às condições do criadouro.

6- An. evansae, An. galvaoi, An. oswaldoi e An. albitarsis mostraram maiores densidades populacionais no inverno, $C x$. (Culex) na primavera, $A d$. squamipennis, no verão, $C x$. (melanoconion) e An. strodei, no outono. Isto evidencia claro processo de sucessão ecológica.

7 - A surpreendente alta densidade larvária de anofelineos no inverno sugere que os mesmos se valem desta estratégia de sobrevivência, permanecendo nessa estação fria na forma de larva.

8 - O Norte do Paraná teve ampliado os seus registros de Culicidae com a catalogaçāo de $C x$. bidens, $C x$. coppenamensis, $C x$. grupo inhibitator, $C x$. vaxus, $C x$. intrincatus, An. intermedius, An. fluminensis, An. evansae e Ur. pulcherrima.

9 - Verificou-se que as barragens nos rios, com conseqüente formação de alagados e colonização das margens internas por plantas aquáticas, favorecem a procriação de anofelineos que poderăo atingir populações muito numerosas.

10 - Tomando-se estas conclusōes como diretriz, é possível inferir o que poderá ocorrer, em relação à culicideofauna, após a construção de 
barragens nos rios de grande porte com vistas ao aproveitamento hidroelétrico. Será prudente, portanto, estabelecer as moradias humanas, nessa área, a distâncias que sejam superiores ao alcance de vôo dos anophelineos. Essa áreas necessitam de vigilância sanitária frequiente.

\section{Referências Bibliográficas}

1. ANDRADE, R.M. de \& RACHOU, R.G. Levantamento preliminar de organismos planctônicos em alguns criadouros do Anopheles darlingi no Sul do Brasil. Rev. Bras. Malariol. Doencas Trop., 6: 481-96, 1954.

2. ANDRADE, J.C. R de et al. Foco de malária no Estado de Sa Paulo (Brasil). Rev. Saúde Pública, 20: 323-6, 1986.

3. CALISHER, C.H. et al. Brus Laguna Virus, a Gamboa Bunya Virus from Aedomya squamipennis collected in Honduras. Am.J. Trop. Med. Hyg, 34; 406-8, 1988.

4. CERQUEIRA, N.L. Distribuiçào geográfica dos mosquitos da Amazônia. Rev. Bras. Entomol., 10:111-68, 1961.

5. CORRÊA, R.R. O Anopbeles ( $N$ ) strodei Root, 1926 como provável vetor de malária. Rev. Biol. Hyg., 9: 104-9, 1938.

6. CORRÊA, R.R. et al. Informaçōes relativas ao Anopbeles albitarsis domesticus, um dos transmissores de malária no Brasil. (Diptera: Culicidae). In: Congresso Brasileiro de Higiene, $7^{\circ}$, Rio de Janeiro, 1949. Anais. Rio de Janeiro, 1949. p. 549-77

7. DYAR apud CALISHER, C.H. et al. Brus Laguna Virus, a Gamboa bunyarvirus from Aedomya squamipennis collected in Honduras, Am. J. Trop. Med. Hyg., 39: 51$129,1981$.

8. GABALDON, A. et al. Especies de la família Culicidae que presentan ornitofilia en Venezulea. Bol. Dir. Malariol. Saneam. Amb. 17: 3-8, 1977 .

9. GABALDON, A. et al. Aedomya squamipennis (Diptera: Culicidae) vector natural de malaria aviaria en Venezuela, Bol. Dir, Malariol. Saneam. Amb., 17: 9-13, 1977.

\section{Agradecimentos}

Ao Prof. Dr. Oswaldo Paulo Forattini, da Faculdade de Saúde Pública da USP, e à sua equipe, pela confirmação da identificação das espécies de Culicidae.

10. GOMES, A. de C. Mecanismos e significado epidemiológico da domiciliação. Rev. Saũde Pública, 20: 385-90, 1986.

11. KNIGHT, K.L. \& STONE, A. A catalog of the mosquitoes of the world (Diptera: Culicidae). Bull. Entomol. Soc. Am., 17: 1-611, 1977.

12. LANE, J. Notas sobre os culicideos de Mato Grosso. Rev. Mus. Paul. 20: 173-210, 1936.

13. LOPES, J. et al. Aedes (Stegomyia) aegypt I. e a culicideofauna associada em área urbana da regiāo Sul, Brasil. Rev. Saúde Püblica, 27: 326-33, 1993

14. LOURENÇO-de-OLIVEIRA, R. et al. Alguns aspectos da ecologia dos mosquitos (Diptera: Culicidae) de uma área de planície (Granjas, Calábria), em Jacarepaguá, Rio de Janeiro, v. Criadouros. Mem. Inst. Oswaldo Cruz, 81: 265-71, 1986.

15. LOZOVEI, A.L. \& LUZ, E. Diptera Culicidae em Curitiba e arredores. I. Ocorrência, Arq. Biol. Tecnol, 19: 25-42, 1976.

16. MAACK, R. Geografia do Estado do Paraná. 2" ed. Rio de Janeiro, J. Olympio, 1981.

17. MITCHELL, C.J. et al. Hostfeeding patterns of argentine mosquitoes (Diptera: Culicidae) collected during and after an epizootic of western equine encephalitis. $J$. Med. Entomol., 24: 260-7, 1987.

18. RACHOU, R.G. Anofelinos do Brasil: comportamento das espécies vetoras de malária, Rev. Bras. Malariol. Doenças Trop., 10: 145-81, 1958.

19. SILVA, M.A.N. da \& LOPES, J. Dados sobre a potencialidade criadoura de Culicidae (Diptera) do Cemitério São Pedro, LondrinaParaná. Semina, 6: 133-9, 1985.

20. TADEI, W.P. Biologia de anofelinos Amazônicos. XI. Estudos em populaçôes de Anopbeles e controle da malária em Ariquemes (Rondônia), Acta Amazôn. 16/17; $151-67,1986 / 87$ 


\begin{abstract}
The objetive of this study is to identity the Culicidae species apt to colonize the waters of a creek with reduced gallery forest in the southern region of Brazil. Captures were performed using a water insect-collecting net. The following species were captured: Aedes crinifer, Aedomya squamipennis, Anopheles fluminensls, An. intermedius, An. albitarsis, An. argyrltarsis, An, evansae, An. strodel, An. galvaol, An. oswaldoi, An, triannulatus, Chagasia fajardi, Culex bidens, $C x$. group coronator, $C x$. eduardoi, $C x$. mollis, $C x$. quinquefasciatus, $C x$. coppenamensis, $C x$. vaxus, $C x$. group inhibitator, Cx. intrincatus, Cx. (Melanoconion) sp, Psorophora saeva (?) and Uranotaenia pulcherrima. As for the species which showed the highest frequency rate, the following aspects were studied: population fluctuation, environmental factor correlated with geographic distribution along the area. It was concluded that superficial waters with reduced gallery forest may serve as a refuge for some Culicidae. This fact may contribute to the dorniciliation process of the species.
\end{abstract}

Culicidae. Ecology, vectors. Larva. 